\title{
Large Follicular Cyst Associated with Upper Third Molar in the Maxillary Sinus with Pterygomaxillary Space Extension: Reflection on a Case Report
}

Carmelo Lo Faro ${ }^{1 *}$, Vincenzo Santillo ${ }^{2}$, Giorgio Lo Giudice ${ }^{1}$, Antonio Troiano ${ }^{1}$, Marco Montella ${ }^{3}$, Salvatore D’Amato ${ }^{2}$, Gianpaolo Tartaro ${ }^{2}$

${ }^{1}$ Department of Neurosciences, Maxillofacial Surgery Unit, Reproductive and Odontostomatological Sciences, University of Naples "Federico II," Naples, Italy; ${ }^{2}$ Department of Medical-Surgical and Dental Specialities, Oral and Maxillofacial Surgery Unit, University of Campania "Luigi Vanvitelli," Caserta, Naples, Italy; ${ }^{3}$ Department of Mental and Physical Health and Preventive Medicine, Pathology Unit, University of Campania "Luigi Vanvitelli," Caserta, Naples, Italy

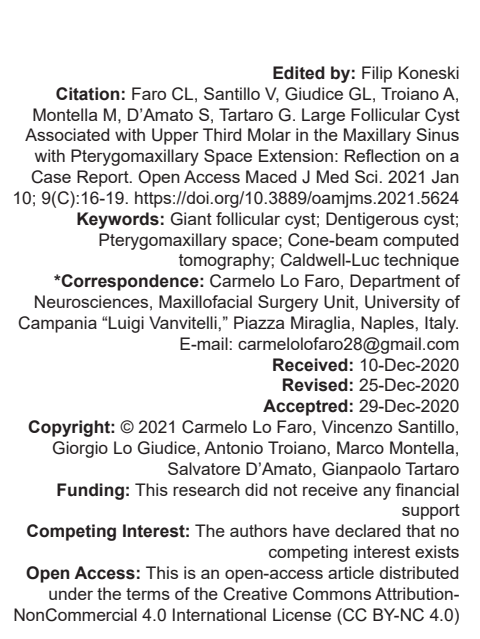

\section{Abstract}

BACKGROUND: Follicular cysts are osteolytic lesions characterized by greater growth, differentiation, and degeneration potentials, compared to inflammatory root cysts. Those connected to upper third molars can disrupt the neighboring teeth and extend to maxillary sinus and adjacent anatomical structures.

CASE PRESENTATION: In this study, we present a case of a large dimension follicular cyst associated with the upper third molar, extended to maxillary antrum and pterygomaxillary space, uncommon for dimensions, involving meso- and sovra-structure describing the clinical diagnostic procedures, and the surgical strategies adopted. The cone-beam computed tomography allowed a very accurate analysis of the lesion. Surgical excision was performed through Caldwell-Luc technique, approaching to the pterygomaxillary space. A 1-year follow-up shows good clinical anatomical, and functional conditions. Histological examination confirmed the diagnosis of follicular cyst.

CONCLUSION: Giant follicular cysts require an accurate pre-operative study due to the delicate structures that may be involved.

\section{Introduction}

Follicular cysts are benign odontogenic lesions consequences of the hydrostatic force exerted by the accumulation of fluid between the enamel crown and enamel epithelium and cystic proliferation of reduced enamel epithelium after the formation of tooth crown [1], [2]. The cyst encloses the crown and is attached to the neck at the cementoenamel junction [2]. They are more frequent in males and even though most often affected teeth are maxillary canines and mandibular third molars, they may also be related with supernumerary or an ectopically erupted tooth. Follicular cysts are osteolytic lesions characterized by greater growth, differentiation, and degeneration potentials, compared to inflammatory root cysts [3]. Those connected to upper third molars can disrupt the neighboring teeth and extend to maxillary sinus and adjacent anatomical structures. This event occurs as a result of compression of the cyst on the osseous thin maxillary boundary walls, causing the thinning of the cortical bone [3], [4].

The expansion of the cysts in the pterygomaxillary fossa, nasal cavity, ethmoidal sinus, or orbit may induce serious morphological, functional, nervous, or infectious complications [5], [6].

For these reasons, large follicular cysts in the maxilla need accurate preoperative study, in relation to the awkward nature of the inner biomorphology of the structures usually involved [4]. In this study, we present a case of a large dimension follicular cyst associated with the upper third molar, extended to maxillary antrum and pterygomaxillary space, uncommon for dimensions, involving meso- and sovra-structure describing the clinical diagnostic procedures, and the surgical strategies adopted. 


\section{Presentation of Case}

A 60-year-old male presented to the oral and maxillofacial department for pain in the left infraorbital region, associated with recurrent episodes of unilateral serous purulent rhinorrhea and ipsilateral nasal obstruction. The clinical examination showed facial asymmetry along with a sensitivity during palpation of the left maxillary and ethmoidal sinus points.

The cone-beam computed tomography (CBCT) revealed a homogenous radiopaque lesion involving the entire left maxillary sinus, with osteolysis of the maxillary walls, extending medially toward the nasal cavity and ethmoidal cells, and posteriorly to the pterygomaxillary fossa (Figure 1).
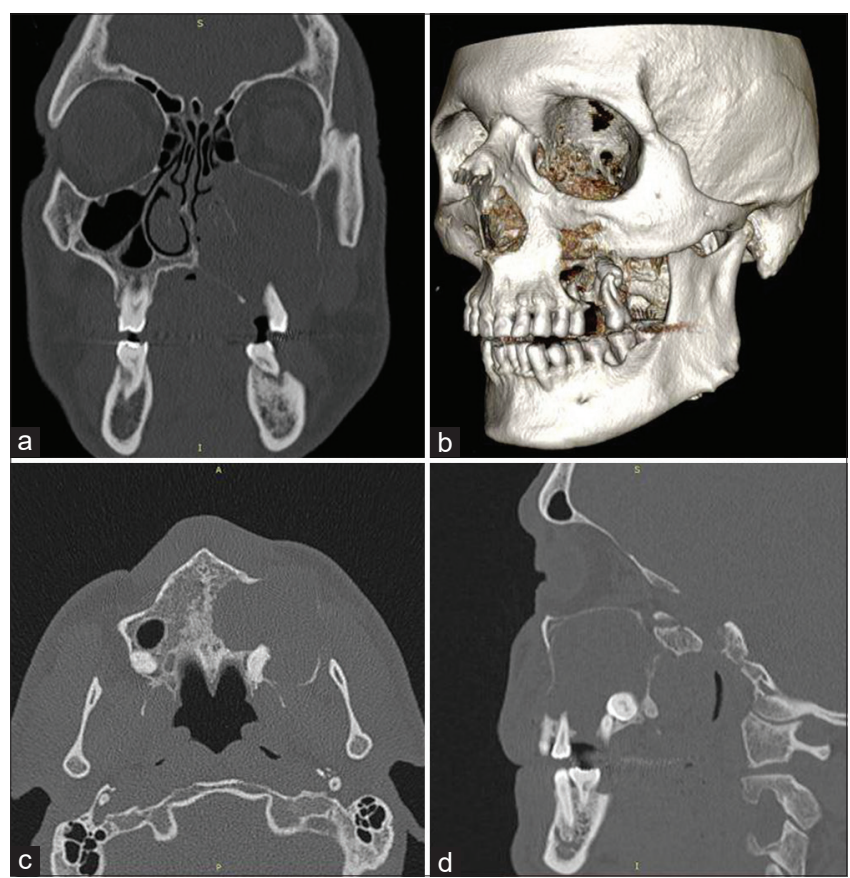

Figure 1: Pre-operative cone-beam computed tomography: (a) Axial showing extension of the lesion to the pterygomaxillary space; (b) $3 D$ reconstruction shows the ectopically impacted upper third molar; (c) coronal showing extension to the left ethmoidal sinus; (d) sagittal showing the extension to the left maxillary antrum

The lesion was arranged by the second molar and the third impacted molar. The lesion had been removed through Caldwell-Luc approach, under general anesthesia, along with the second molar and the impacted third molar (Figure 2).

As a result of the deficiency of bone in the posterior part of the alveolar ridge, two planes wound closure was applied to avoid oroantral fistula. The removed cystic lesion, inserted at the neck of the tooth 2.8 , was estimated at $6 \mathrm{~cm}$ in the largest diameter.

Macroscopical examination showed a fragmented voluminous cystic formation (Figure 3a), measuring $6 \mathrm{~cm} \times 2 \mathrm{~cm}, 2 \mathrm{~cm} \times 1.6 \mathrm{~cm}$, which histologically was partially lined by stratified squamous epithelium without atypia (Figure $3 b$ ). The cystic wall was composed by fibrotic stroma, with mild chronic inflammation and evident aggregates of cholesterol crystals and numerous siderophages (Figure 3c). At the periphery of the cyst also, fragments of lamellar bone were present (Figure 3a). Thus, diagnosis of follicular cyst was performed.

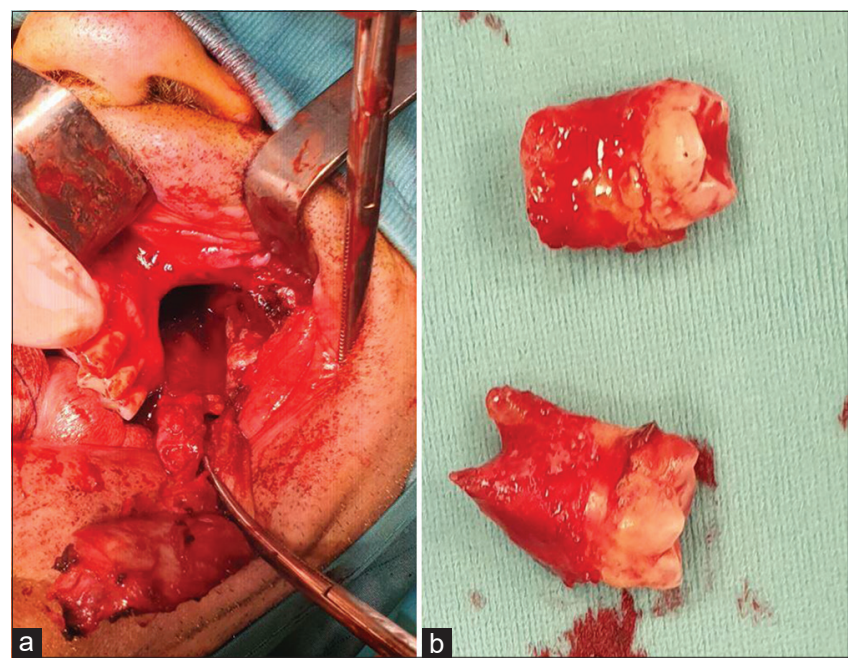

Figure 2: Surgical procedure: (a) Lesion removed through CaldwellLuc approach, along with (b) the second molar and the impacted third molar

One-year follow-up clinical and CBCT examination shows a good anatomical and functional recovering of antro-pterygo-maxillary structures without any recurrence of the lesions and integrity of the anatomical structures (Figure 4).

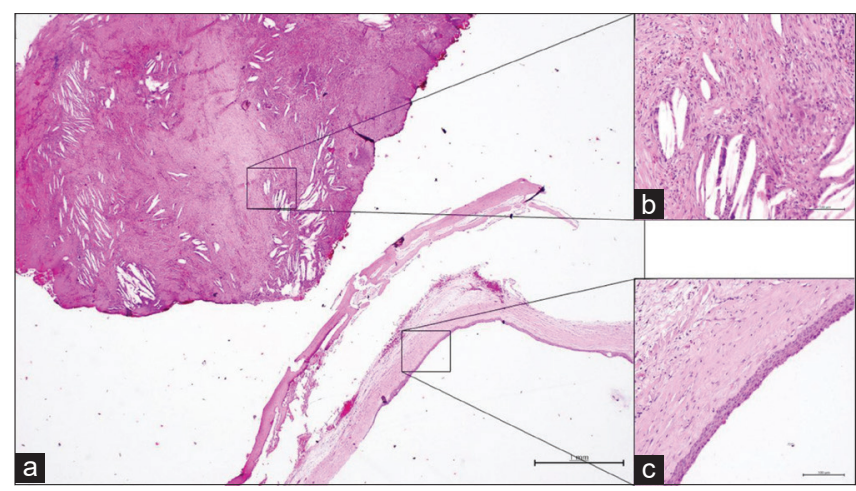

Figure 3: Histological pattern: (a) At low-power magnification, fragmented cystic lesion with lamellar bone $(H$ and $E$ stain, $2 \times)$; (b) cyst lined by squamous cell epithelium without atypia ( $H$ and $E$ stain, 20x); (c) fibrotic stroma with chronic inflammation, aggregates of cholesterol crystals and siderophages ( $H$ and $E$ stain, 20x)

\section{Discussion}

Among developmental cysts, follicular cysts are the most prevalent type, and after radicular cysts, it is the second most common cystic lesion of odontogenic origin. Follicular cysts constitute $24 \%$ of all cysts in the jaws [7]. Most are found in the mandible with the prevalence of dentigerous cyst which is nearly twice more common in mandible than the maxilla [8]. 


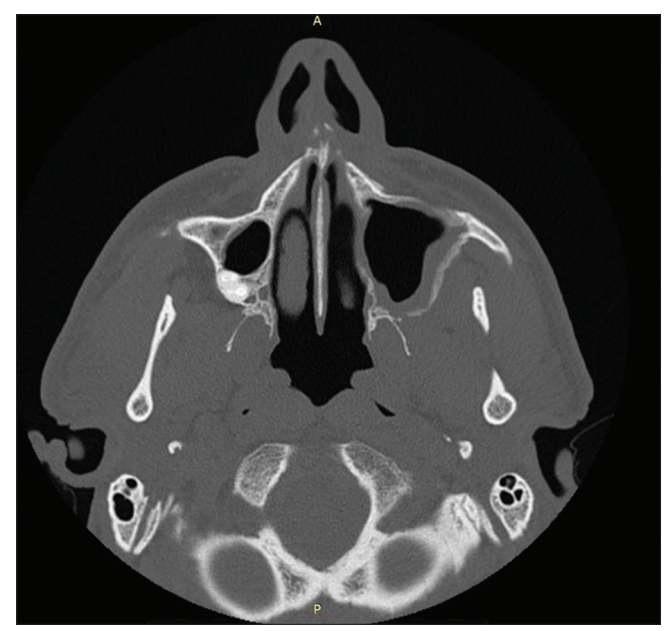

Figure 4: One-year follow-up cone-beam computed tomography: Normal expansion of the maxillary sinus, with no signs of any recurrence of the lesions

Follicular cysts associated with ectopic teeth within the maxillary sinus are uncommon condition according to Buyukkurt et al. that reported only 17 cases in a 30 -year literature review [9].

Follicular cysts are often discovered incidentally during routine radiographic examination. Radiologically, follicular cysts have a typical appearance, showing as unilocular radiolucent lesions with well-defined sclerotic borders [6]. This appearance, however, is not pathognomonic and odontogenic keratocyst, radicular cyst, adenomatoid odontogenic tumor, ameloblastoma, calcifying odontogenic cyst, and ameloblastic fibroma which may present same radiographic property [10]. Therefore, histopathologic investigation is mandatory for final diagnosis [11].

Pathological proliferation and cystic degeneration of the follicular tissue of the superior impacted maxillary third molars can cause particular clinical conditions, especially when the lesion reaches very large dimensions [12]. Orbital signs such as epiphora, exophthalmia, and diplopia could be present due to the expansion of the lesion at this level, displacing the orbital floor and/or lamina papyracea [8], [13].

Precisely for these reasons, an early diagnosis is fundamental to avoid the development of a giant follicular cysts in the maxilla that needs an accurate preoperative study, in relation, also, to the delicate nature of the inner biomorphology of the structures usually involved [14], [15].

Only few cases of giant follicular cyst involving the maxillary sinus and the pterygomaxillary space have been reported in the international literature, and also for these reasons, the proper diagnostic and therapeutic approach remains controversial [14], [15].

In the present case, the follicular cyst was associated with impacted upper third molar in the maxillary sinus with osteolysis of the maxillary walls, extending medially toward the nasal cavity and ethmoidal cells, and posteriorly to the pterygomaxillary fossa. The orbital structures denoted a border of the lesions, with possibility of secondary involvement by means of the surgical intervention. The patient complained pain in the left infraorbital region, and expansile swelling overlying the left maxillary sinus, associated with recurrent episodes of unilateral serous purulent rhinorrhea and ipsilateral nasal obstruction, without orbital symptoms. The treatment of maxillary follicular cysts consists of enucleating the lesion together with the extraction of the involved tooth. The surgical access should be large enough to allow complete excision of the lesion, especially if it extends in the soft perimaxillary tissues. Endoscopic surgical treatment can lower the rate of perioperative complications and is recommended in cases of orbital and paranasal sinuses extension [16], [17]. The pathological examination is mandatory. The importance resides in detection of mural ameloblastoma, epidermoid carcinoma, and mucoepidermoid carcinomas developed from the epithelial wall of follicular cysts. Due to the recurrence of a dentigerous cyst from residual components of cyst lining, complete removal of the cyst is very important for the good prognosis and lack of recurrence [18].

\section{Conclusions}

The most efficient treatment of maxillary follicular cysts consists in the surgical removal of the lesion along with the involved tooth. Pre-operative evaluation and rigorous planning are essential, especially in large-sized lesions.

Inflammatory complications and extension into adjacent structures, indeed, might make excision even more arduous due to pathological changes in the normal anatomy and the modification of the surgical planes. Complete excision is mandatory to avoid recurrence and pathological examination is outmost importance.

\section{References}

1. Kasat VO, Karjodkar FR, Laddha RS. Dentigerous cyst associated with an ectopic third molar in the maxillary sinus: A case report and review of literature. Contemp Clin Dent. 2012;3(3):373-6. https://doi.org/10.4103/0976-237x.103642 PMid:23293505

2. Abrahams JJ, Oliverio PJ. Odontogenic cysts: Improved imaging with a dental CT software program. AJNR Am J Neuroradiol. 1993;14(2):367-74 PMid:8456714

3. Hirose K, Suzuki S, Kuroda T. A long-term follow-up case of multiple impacted teeth associated with large follicular cyst in maxilla. Kokubyo Gakkai Zasshi. 2000;67(2):213-20. https://doi. org/10.5357/koubyou.67.213 


\section{PMid:10921246}

4. Srinivasa Prasad T, Sujatha G, Niazi TM, Rajesh P. Dentigerous cyst associated with an ectopic third molar in the maxillary sinus: A rare entity. Indian J Dent Res. 2007;18(3):141-3. https:// doi.org/10.4103/0970-9290.33793

PMid: 17687180

5. Metzger MC, Wagner KW, Hohlweg-Majert B, Voss PJ, Schoen R, Schmelzeisen R. Diplopia and acute rectus muscle palsy as symptoms of an infected follicular cyst of a maxillary right third molar: A case report. Quintessence Int. 2007;38(7):571-4. PMid:17694213

6. Kara MI, Yanik S, Altan A, Oznalcin O, Ay S. Large dentigerous cyst in the maxillary sinus leading to diplopia and nasa obstruction: Case report. J Istanb Univ Fac Dent. 2015;49(2):4650. https://doi.org/10.17096/jiufd.10506

\section{PMid:28955536}

7. Tournas AS, Tewfik MA, Chauvin PJ, Manoukian JJ. Multiple unilateral maxillary dentigerous cysts in a non-syndromic patient: A case report and review of the literature. Int $\mathrm{J}$ Pediatr Otorhinolaryngol Extra. 2006;1(2):100-6. https://doi. org/10.1016/j.pedex.2005.12.005

8. Girish G, Mahesh Kumar R, Umashankar DN, Sharma R, Veeresh M, Bhandari A. Dentigerous cyst in maxillary sinus: A rare occurrence. Int J Oral Maxillofac Pathol. 2011;2(2):20-3.

9. Buyukkurt MC, Omezli MM, Miloglu O. Dentigerous cyst associated with an ectopic tooth in the maxillary sinus: A report of 3 cases and review of the literature. Oral Surg Oral Med Oral Pathol Oral Radiol Endod. 2010;109(1):67-71. https://doi. org/10.1016/j.tripleo.2009.07.043

PMid:19875313

10. Troiano A, Lo Giudice G, De Luca R, Lo Giudice F, D'Amato S, Tartaro G, et al. Salvage of dental implant located in mandibular odontogenic cyst. A conservative surgical treatment proposal. Dent J (Basel). 2020;8(2):49. https://doi.org/10.3390/dj8020049 PMid:32403226
11. Panarese I, Lucà S, Ronchi A. Gingival manifestation of a therapy-related acute myelomonocytic leukemia in a patient with previously treated with $\mathrm{R}-\mathrm{CHOP}$ scheme for diffuse large B-cell lymphoma. Oral Maxillofac Surg Cases. 2020;6(4):100182. https://doi.org/10.1016/j.omsc.2020.100182

12. Akyol UK, Salman IA. A case of an extensive dentigerous cyst in the maxillary sinus leading to epiphora and nasal obstruction. J Emerg Med. 2012;43(6):1004-7. https://doi.org/10.1016/j. jemermed.2010.11.045 PMid:21310578

13. Falcone F, Lazow SK, Berger JR, Gold BD. Superior orbital fissure syndrome. Secondary to infected dentigerous cyst of the maxillary sinus. N Y State Dent J. 1994;60(9):62-4 PMid:7808720

14. Bernardi S, Scarsella S, Di Fabio D, Oliva A, Di Girolamo M, Continenza MA, et al. Giant follicular cysts extended in pterygomaxillary fossa, antro-naso-ethmoidal and orbital space associated to exophtalmos and diplopia in young patients. Oral Maxillofac Surg Cases. 2018;4(1):17-22. https://doi. org/10.1016/j.omsc.2018.02.002

15. Moldovan MA, Rotaru H, Roman CR. Giant follicular cyst with maxillary sinus and pterygomaxillary space extension. Ann Ital Chir. 2020;9:S2239253X20032983. PMid:32588835

16. Romano A, Lo Faro C, Salzano G, Dell'Aversana Orabona G, Petrocelli M, Corvino R, et al. Synovial chondromatosis of temporomandibular joint spreading into the cranial space. J Oral Maxillofac Surg Med Pathol. 2018;30(3):267-71. https:// doi.org/10.1016/j.ajoms.2018.01.006

17. Barca I, Lo Faro C, Cordaro R, Novembre D, Mignogn C, Cristofaro MG. Intramuscular lipoma involving the masticator space: A case report. J Oral Maxillofac Surg Med Pathol. 2019;31(3):208-11. https://doi.org/10.1016/j.ajoms.2019.02.003

18. Beriat GK, Beriat NÇ, Yalçınkaya E. Ectopic molar tooth in the maxillary sinus: A case report. Clin Dent Res. 2011;35(2):35-40. 